\title{
Article: Health Economics
}

\section{Cost-utility analysis of liraglutide compared with sulphonylurea or sitagliptin, all as add-on to metformin monotherapy in Type $\mathbf{2}$ diabetes mellitus}

\author{
M. J. Davies ${ }^{1}$, B. D. Chubb², I. C. Smith ${ }^{2}$ and W. J. Valentine ${ }^{3}$ \\ ${ }^{1}$ Department of Cardiovascular Sciences, University of Leicester, Leicester, ${ }^{2}$ Novo Nordisk Ltd, Crawley, West Sussex, UK and ${ }^{3}$ Ossian Health Economics \\ and Communications, Basel, Switzerland \\ Accepted 19 August 2011
}

\section{Abstract}

Aim To investigate the cost-effectiveness of liraglutide as add-on to metformin vs. glimepiride or sitagliptin in patients with Type 2 diabetes uncontrolled with first-line metformin.

Methods Data were sourced from a clinical trial comparing liraglutide vs. glimepiride, both in combination with metformin, and a clinical trial comparing liraglutide vs. sitagliptin, both as add-on to metformin. Only the subgroup of patients in whom liraglutide was added to metformin monotherapy was included in the cost-utility analysis. The CORE Diabetes Model was used to simulate outcomes and costs with liraglutide 1.2 and $1.8 \mathrm{mg}$ vs. glimepiride and vs. sitagliptin over patients' lifetimes. Treatment effects were taken directly from the trials. Costs and outcomes were discounted at $3.5 \%$ per annum and costs were accounted from a third-party payer (UK National Health System) perspective.

Results Treatment with liraglutide 1.2 and $1.8 \mathrm{mg}$ resulted, respectively, in mean increases in quality-adjusted life expectancy of $0.32 \pm 0.15$ and $0.28 \pm 0.14$ quality-adjusted life years vs. glimepiride, and $0.19 \pm 0.15$ and $0.31 \pm 0.15$ quality-adjusted life years vs. sitagliptin, and was associated with higher costs of $£ 3003 \pm £ 678$ and $£ 4688 \pm £ 639$ vs. glimepiride, and $£ 1842 \pm £ 751$ and $£ 3224 \pm £ 683$ vs. sitagliptin, over a patient's lifetime. Both liraglutide doses were cost-effective, with incremental cost-effectiveness ratios of $£ 9449$ and $£ 16501$ per quality-adjusted life year gained vs. glimepiride, and $£ 9851$ and $£ 10465$ per quality-adjusted life year gained vs. sitagliptin, respectively.

Conclusions Liraglutide, added to metformin monotherapy, is a cost-effective option for the treatment of Type 2 diabetes in a UK setting.

Diabet. Med. 29, 313-320 (2012)

Keywords cost-effectiveness, liraglutide, Type 2 diabetes, UK

Abbreviations NICE, National Institute for Health and Clinical Excellence; QALY, quality-adjusted life year

\section{Introduction}

Diabetes is among the most common chronic illnesses worldwide, with Type 2 diabetes mellitus accounting for approximately $90 \%$ of all cases [1]. Type 2 diabetes is progressive and is characterized by increased insulin resistance, generally associated with obesity, and deteriorating $\beta$-cell

Correspondence to: Professor Melanie J. Davies, Department of Cardiovascular Sciences, Leicester Royal Infirmary, Infirmary Square, Leicester, LE1 5WW, UK. E-mail: melanie.davies@uhl-tr.nhs.uk

Re-use of this article is permitted in accordance with the Terms and Conditions set out at http://wileyonlinelibrary.com/onlineopen\#OnlineOpen_ Terms function, resulting in chronic hyperglycaemia. As the disease progresses, so do the micro- and macrovascular complications associated with it, which have a negative impact on the quality of life of patients and pose a huge economic burden to the health system [2,3]. For example, in the UK, the cost of Type 2 diabetes accounts for $7-12 \%$ of the total National Health Service (NHS) expenditure [4].

The risk of micro- and macrovascular complications is strongly associated with hyperglycaemia, and each reduction of $11 \mathrm{mmol} / \mathrm{mol}(1 \%)$ in $\mathrm{HbA}_{1 \mathrm{c}}$ significantly reduces the risk of developing these complications in patients with Type 2 diabetes [5]. In the UK, the National Institute for Health and Clinical Excellence (NICE) recently issued recommendations for the optimum management of Type 2 diabetes, taking into 
consideration the effectiveness, safety and cost-effectiveness of the available treatments (NICE, 2009) [6]. NICE recommends lifestyle modifications and metformin as first-line therapy, with the subsequent stepwise additions of a sulphonylurea and insulin. A thiazolidinedione or a dipeptidyl peptidase-4 (DPP-4) inhibitor may be considered as second-line options in place of a sulphonylurea if there is a significant risk of hypoglycaemia, or if a sulphonylurea is contraindicated or not tolerated. Sitagliptin (a DPP-4 inhibitor) or a thiazolidinedione can be considered as third-line therapy in place of insulin if insulin is unacceptable. Exenatide may also be considered as a third-line option in combination with metformin and a sulphonylurea in patients with a BMI above $35 \mathrm{~kg} / \mathrm{m}^{2}$ and problems associated with high weight, or BMI under $35 \mathrm{~kg} / \mathrm{m}^{2}$ if insulin is unacceptable because of occupational implications, or if weight loss would benefit other co-morbidities [6]. The place of liraglutide $\left(\right.$ Victoza $^{\circledR}$; Novo Nordisk A/S, Bagsvaerd, Denmark) in therapy has also been evaluated recently by NICE [7].

Recommendations advocate the use of liraglutide $1.2 \mathrm{mg}$ daily in triple therapy (with metformin and a sulphonylurea or metformin and a thiazolidinedione) under the same conditions described for exenatide, and in dual therapy (with metformin or a sulphonylurea) if metformin or sulphonylureas and thiazolidinediones or DPP-4 inhibitors cannot be tolerated or are contraindicated [7]. The American Diabetes Association and the European Association for the Study of Diabetes issued similar recommendations in a consensus algorithm based on effectiveness and safety data from clinical trials and on clinical experience, taking into account benefits, risks and costs of the different available treatments [8]. In clinical trials, glucagonlike peptide 1 (GLP-1) receptor agonists, such as liraglutide and exenatide, have been shown to reduce $\mathrm{HbA}_{1 \mathrm{c}}$ to at least the same, and often to a greater, extent than traditional oral hypoglycaemic agents and both Glucagon-like peptide (GLP-1) receptor agonists and DPP-4 inhibitors such as Sitagliptin, have the additional advantages of reducing the risk of hypoglycaemia, as their insulinotropic effect is glucosedependent, and inducing weight loss (in the case of GLP-1 receptor agonists) or being weight-neutral (in the case of DPP-4 inhibitors) [9]. Additionally, GLP-1 receptor agonists have been shown to have a positive effect on systolic blood pressure [9]. Despite these advantages, sulphonylureas continue to be the preferred second-line choice after metformin, with incretinbased therapies only recommended as second- or third-line therapies in special circumstances $[6,8]$. The fact that incretinbased therapies are considered more expensive may contribute to these therapies not being recommended more widely.

Liraglutide is a GLP-1 analogue approved in 2009 for use in Europe, including the UK. Because of its recent approval, studies evaluating the cost-effectiveness of liraglutide are scarce. The aim of our study was to investigate the costeffectiveness of liraglutide as add-on to metformin compared with glimepiride or sitagliptin in patients failing treatment with first-line metformin.

\section{Patients and methods}

\section{Data sources}

The cost-utility evaluation carried out in this study is based on patients who participated in two studies performed as part of the phase III clinical development programme for liraglutide: a study comparing liraglutide vs. glimepiride (LEAD-2 study), both in combination with metformin, and a study comparing liraglutide vs. sitagliptin, both also in combination with metformin [10,11]. In the LEAD-2 study, adults with Type 2 diabetes and $\mathrm{HbA}_{1 \mathrm{c}}$ between 53 and $97 \mathrm{mmol} / \mathrm{mol}(7-11 \%)$ (if previously treated with oral hypoglycaemic agent monotherapy for at least 3 months) or $\mathrm{HbA}_{1 \mathrm{c}}$ between 53 and $86 \mathrm{mmol} / \mathrm{mol}(7-10 \%)$ (if previously treated with oral hypoglycaemic agent combination therapy for at least 3 months) were included. Additional inclusion criteria were age between 18 and 80 years and BMI $\leq 40 \mathrm{~kg} / \mathrm{m}^{2}$. To facilitate recruitment into the trial, previous treatment with other oral anti-diabetes drugs, as monotherapy or in combination, was allowed [10]. However, only the subgroup of patients in which liraglutide or glimepiride was added to metformin monotherapy (approximately 30\% of the total trial population) was included in the cost-utility analysis presented here, as this was considered to be more reflective of actual clinical practice. In the liraglutide vs. sitagliptin study, adults with Type 2 diabetes, previously treated with metformin monotherapy for at least 3 months and with $\mathrm{HbA}_{1 \mathrm{c}}$ between 58 and $86 \mathrm{mmol} / \mathrm{mol}$ $(7.5-10.0 \%)$ were included. Additional inclusion criteria were age between 18 and 80 years and BMI $\leq 45 \mathrm{~kg} / \mathrm{m}^{2}$ [11]. Demographic characteristics of the patients enrolled in these studies have previously been described $[10,11]$.

\section{The CORE Diabetes Model}

The cost-utility evaluation presented here was carried out using the CORE Diabetes Model, details of which have been published previously by Palmer et al. [12]. The CORE diabetes model is a validated [13] non-product-specific policy analysis tool based on a series of 15 sub-models that simulate major complications of diabetes: cardiovascular disease, stroke, neuropathy, foot ulcer/amputation, eye disease, nephropathy, hypoglycaemia, lactic acidosis and non-specific mortality [12]. For each submodel, a combination of semi-Markov model structure and Monte Carlo simulations were used. This structure allows patients to develop multiple complications within each model cycle and over the simulation period. The model projects outcomes for populations, considering baseline cohort characteristics, past history of complications, concomitant medications, current and future diabetes management, screening strategies and changes in physiological variables over time. In this way, incidence of complications, life expectancy, quality-adjusted life expectancy and total costs within populations can be calculated. The results can be expressed in 
terms of quality-adjusted life years (QALYs) gained and incremental cost-effectiveness ratios, i.e. the cost per QALY gained. An incremental cost-effectiveness ratio threshold of $£ 20$ 000-30 000 per QALY gained is generally considered to represent good value for money in the UK [14].

\section{Simulation cohorts and treatments}

A simulated cohort of patients was defined (Table 1), with baseline demographics and complications taken from the respective clinical trial used in the analysis. Treatment effects with liraglutide (1.2 and $1.8 \mathrm{mg}$ ) vs. glimepiride and liraglutide (1.2 and $1.8 \mathrm{mg}$ ) vs. sitagliptin were taken directly from the clinical trials (Table 2). Treatment duration was set to 5 years, after which basal insulin therapy was started in an attempt to replicate clinical practice. Simulations were run over patients' lifetimes to capture all events and complications related to the progression of Type 2 diabetes.

Table 1 Baseline patient characteristics in the liraglutide vs. glimepiride and liraglutide vs. sitagliptin studies

\begin{tabular}{|c|c|c|}
\hline & $\begin{array}{l}\text { Liraglutide } \\
\text { vs. glimepiride } \\
(n=263)^{*}\end{array}$ & $\begin{array}{l}\text { Liraglutide } \\
\text { vs. sitagliptin } \\
(n=635)\end{array}$ \\
\hline \multicolumn{3}{|l|}{ Patient demographics } \\
\hline Age (years) & $55.8(9.0)$ & $55.3(9.2)$ \\
\hline $\begin{array}{l}\text { Diabetes duration } \\
\text { (years) }\end{array}$ & $6(5)$ & $6(5)$ \\
\hline Proportion male (\%) & 54.2 & 52.9 \\
\hline \multicolumn{3}{|l|}{ Risk factors } \\
\hline $\mathrm{HbA}_{1 \mathrm{c}}(\mathrm{mmol} / \mathrm{mol})$ & $67(8.9)$ & $68(6.5)$ \\
\hline$(\%)$ & $8.3(1.1)$ & $8.4(0.8)$ \\
\hline $\begin{array}{l}\text { Systolic blood pressure } \\
(\mathrm{mmHg})\end{array}$ & $130.6(14.0)$ & $132.2(14.5)$ \\
\hline $\begin{array}{l}\text { Body mass index } \\
\left(\mathrm{kg} / \mathrm{m}^{2}\right)\end{array}$ & $31.0(4.7)$ & $32.8(5.2)$ \\
\hline $\begin{array}{l}\text { Total cholesterol } \\
(\mathrm{mmol} / \mathrm{l})\end{array}$ & $4.88(1.12)$ & $4.09(1.14)$ \\
\hline HDL-C (mmol/l) & $1.29(0.33)$ & $1.16(0.31)$ \\
\hline LDL-C $(\mathrm{mmol} / \mathrm{l})$ & $3.11(0.89)$ & $2.65(0.82)$ \\
\hline Triglycerides $(\mathrm{mmol} / \mathrm{l})$ & $2.19(1.66)$ & $2.38(2.22)$ \\
\hline Current smoker $(\%) \dagger$ & $19.3 *$ & 19.3 \\
\hline Cigarettes $/ \mathrm{day}^{\dagger}$ & 10 & 10 \\
\hline $\begin{array}{l}\text { Alcohol consumption } \\
(\mathrm{Oz} / \text { week }) \dagger\end{array}$ & 5 & 5 \\
\hline \multicolumn{3}{|l|}{ Ethnic group (\%) } \\
\hline Caucasian & 88.5 & 90.0 \\
\hline Black & 2.4 & 7.5 \\
\hline Hispanic & 0 & 0 \\
\hline Native American & 0 & 0.5 \\
\hline Asian/Pacific Islander & 9.1 & 0.2 \\
\hline
\end{tabular}

"Subgroup of patients from LEAD-2 in which liraglutide or glimepiride was added to metformin monotherapy.

†Smoking status from Scottish Diabetes Survey 2007 [24]; cigarette and alcohol consumption are estimates.

The numbers in parentheses indicate standard deviation.

\section{Costs and utilities}

Costs were accounted from a third-party payer (National Health Service) perspective. Where possible, unit costs for complications were derived from UK-specific published sources in patients with Type 2 diabetes and inflated to 2008 values, the latest available at the time of analysis, using the composite National Health Service price inflation index from the Personal Social Services Research Unit (PSSRU). A summary of the costs of medicines and complications is given in the Supporting Information (Table S1). The utilities used in the base case presented here are summarized in the Supporting Information (Table S2). The costs of medicines, self-monitored blood glucose testing equipment and needles were taken from the Monthly Index of Medical Specialities (MIMS) August 2009 [15]. Utilities and disutilities (i.e. measures of the impact on quality of life) associated with complications of diabetes were obtained from the literature and, where possible, taken from populations with Type 2 diabetes. Discount rates of $3.5 \%$ per annum for both costs and clinical outcomes were applied in the base case.

\section{Sensitivity analyses}

To assess the impact of varying the key assumptions and outcomes used in the base-case analysis, several sensitivity analyses were performed: treatment duration was set to 3 and 8 years; an alternative weight progression was used in which, when treatment is switched, BMI reverts to baseline level and then increases as predicted with insulin treatment; discount rates were set to 0 and $6 \%$ for both costs and outcomes; and hypoglycaemia disutility was removed and also set to 0.0052 , as used in the technology appraisal of insulin glargine carried out by NICE [18]. Additional analyses to investigate the contribution of individual clinical effects (weight, cholesterol and triglycerides, systolic blood pressure and $\mathrm{HbA}_{1 \mathrm{c}}$ ) to quality-adjusted life expectancy were also performed. The values used in the sensitivity analyses were derived from expert consensus or were previously used by, or recommended by, NICE in its Guide to the Methods of Technology Appraisal [16,17]. The results of these analyses are presented as approximate relative impacts of the base-case benefit. It should be noted that these values represent crude approximations (and therefore will not typically sum to $100 \%$ ), as sensitivity analyses reflecting changes in multiple clinical variables have a complex impact on outcomes (in relation to the base case).

\section{Statistical methodology}

A non-parametric bootstrapping approach was used for this health economic analysis. Using second-order Monte Carlo simulation, Type 2 diabetes progression was simulated in 1000 patients through the model 1000 times to calculate the mean and standard deviation of life expectancy, quality-adjusted life expectancy, and costs [12]. The results from the bootstrapped 
Table 2 Treatment effects in the liraglutide vs. glimepiride (previous metformin monotherapy subgroup only) and liraglutide vs. sitagliptin studies

\begin{tabular}{|c|c|c|c|c|c|c|}
\hline \multirow[b]{2}{*}{ Risk factor } & \multicolumn{3}{|c|}{ Liraglutide vs. glimepiride } & \multicolumn{3}{|c|}{ Liraglutide vs. sitagliptin } \\
\hline & $\begin{array}{l}\text { Liraglutide } \\
1.2 \text { mg }+ \\
\text { metformin } \\
n=91\end{array}$ & $\begin{array}{l}\text { Liraglutide } \\
1.8 \mathrm{mg}+ \\
\text { metformin } \\
n=83\end{array}$ & $\begin{array}{l}\text { Sulphonylurea } \\
+ \text { metformin } \\
n=89\end{array}$ & $\begin{array}{l}\text { Liraglutide } \\
1.2 \text { mg } \\
+ \text { metformin } \\
n=214\end{array}$ & $\begin{array}{l}\text { Liraglutide } \\
1.8 \mathrm{mg} \\
+ \text { metformin } \\
n=211\end{array}$ & $\begin{array}{l}\text { Sitagliptin } \\
100 \mathrm{mg} \\
+ \text { metformin } \\
n=210\end{array}$ \\
\hline \multirow[t]{2}{*}{$\begin{array}{l}\text { Change in } \mathrm{HbA}_{1 \mathrm{c}} \\
(\mathrm{mmol} / \mathrm{mol})(\%)\end{array}$} & $-13.7(11.2)$ & $-14.2(10.8)$ & $-12.7(10.6)$ & $-13.1(11.0)$ & $-16.4(9.7)$ & $-10.0(11.6)$ \\
\hline & $-1.25(1.02)$ & $-1.30(0.99)$ & $-1.16(0.97)$ & $-1.24(1.04)$ & $-1.50(0.89)$ & $-0.90(1.04)$ \\
\hline $\begin{array}{l}\text { Change in systolic } \\
\text { blood pressure } \\
(\mathrm{mmHg})\end{array}$ & $-3.33(12.90)$ & $-1.18(12.70)$ & $2.26(12.65)$ & $-0.55(13.23)$ & $-0.72(13.14)$ & $-0.94(13.17)$ \\
\hline $\begin{array}{l}\text { Change in total } \\
\text { cholesterol } \\
(\mathrm{mmol} / \mathrm{l})^{*}\end{array}$ & $-0.02(0.82)$ & $-0.30(0.80)$ & $0.09(0.08)$ & $-0.03(0.82)$ & $-0.17(0.80)$ & $-0.02(0.80)$ \\
\hline Change in LDL-C $(\mathrm{mmol} / \mathrm{l})^{*}$ & $0.15(0.68)$ & $0.13(0.67)$ & $0.22(0.67)$ & $0.08(0.69)$ & $0.05(0.67)$ & $0.13(0.68)$ \\
\hline Change in HDL-C $(\mathrm{mmol} / \mathrm{l})^{* *}$ & $0.02(0.21)$ & $-0.03(0.20)$ & $-0.02(0.20)$ & $0.00(0.17)$ & $0.00(0.17)$ & $0.00(0.17)$ \\
\hline $\begin{array}{l}\text { Change in triglycerides } \\
(\mathrm{mmol} / \mathrm{l})^{*}\end{array}$ & $-0.44(1.29)$ & $-0.26(1.26)$ & $-0.25(1.26)$ & $-0.19(1.42)$ & $-0.43(1.37)$ & $-0.40(1.38)$ \\
\hline Change in BMI $\left(\mathrm{kg} / \mathrm{m}^{2}\right)$ & $-0.64(0.95)$ & $-0.75(1.11)$ & $0.48(3.69)$ & $-1.00(0.08)$ & $-1.18(0.08)$ & $-0.34(0.08)$ \\
\hline $\begin{array}{l}\text { Major hypo event rate } \\
\text { (per } 100 \text { patient years) }\end{array}$ & 0 & 0 & 0 & 1 & 0 & 0 \\
\hline $\begin{array}{l}\text { Minor hypo event rate } \\
\text { (per } 100 \text { patient years) }\end{array}$ & 4.9 & 17.1 & 217.2 & 17.8 & 16.1 & 10.6 \\
\hline
\end{tabular}

Data are mean (SD).

*The model accepts values in $\mathrm{mg} / \mathrm{dl}$. The following factors have been used to convert to mmol/l: 0.0259 for total cholesterol, LDL-C and HDL-C, and 0.0113 for triglycerides.

simulations were used to create cost-effectiveness acceptability curves.

\section{Results}

\section{Base-case analyses}

\section{Liraglutide vs. glimepiride}

Treatment with liraglutide 1.2 and 1.8 mg resulted, respectively, in a mean increase in quality-adjusted life expectancy of $0.32 \pm$ 0.15 QALYs and $0.28 \pm 0.14$ QALYs, and was associated with higher costs of $£ 3003 \pm £ 678$ and $£ 4688 \pm £ 639$ over a patient's lifetime, compared with glimepiride. The estimated incremental cost-effectiveness ratios for liraglutide 1.2 and $1.8 \mathrm{mg}$ vs. glimepiride were, respectively, $£ 9449$ and $£ 16501$ per QALY gained (Table 3). At a willingness to pay of $£ 20000$ per QALY gained, liraglutide $1.2 \mathrm{mg}$ is a cost-effective treatment option in over $88 \%$ of cases, whereas liraglutide $1.8 \mathrm{mg}$ is a costeffective treatment option in over $65 \%$ of cases. If the willingness-to-pay threshold is increased to $£ 30000$, the probability that the treatment will be cost-effective increases to over $93 \%$ for liraglutide $1.2 \mathrm{mg}$ and $83 \%$ for liraglutide $1.8 \mathrm{mg}$ (Fig. 1).

\section{Liraglutide vs. sitagliptin}

Compared with sitagliptin, mean increases in quality-adjusted life expectancy of $0.19 \pm 0.15$ QALYs and $0.31 \pm 0.15$
QALYs, and higher costs of $£ 1842 \pm £ 751$ and $£ 3224 \pm £ 683$ were associated with liraglutide 1.2 and $1.8 \mathrm{mg}$, respectively, over a patient's lifetime. The estimated incremental costeffectiveness ratios for liraglutide 1.2 and $1.8 \mathrm{mg}$ vs. sitagliptin were, respectively, $£ 9851$ and $£ 10465$ per QALY gained (Table 3). At a willingness to pay of $£ 20000$, liraglutide $1.2 \mathrm{mg}$ is a cost-effective treatment option in over $77 \%$ of cases, while liraglutide $1.8 \mathrm{mg}$ is a cost-effective treatment option in over $85 \%$ of cases. The probability that the treatment will be cost-effective increases to $82 \%$ for liraglutide $1.2 \mathrm{mg}$ and $92 \%$ for liraglutide $1.8 \mathrm{mg}$ when the willingness-to-pay threshold is increased to $£ 30000$.

\section{Sensitivity analyses}

Liraglutide vs. glimepiride and liraglutide vs. sitagliptin Decreasing the discount rate resulted in a lower incremental cost-effectiveness ratio with liraglutide $1.2 \mathrm{mg}$, while increasing the discount rate increased the incremental cost-effectiveness ratio. Reducing treatment duration from 5 to 3 years resulted in a lower incremental cost-effectiveness ratio for liraglutide $1.2 \mathrm{mg}$ (Table 4). In the shorter treatment duration simulation, the full clinical benefit of liraglutide was achieved, but the cost was reduced as liraglutide pharmacy costs were only accounted for 3 years. Increasing treatment duration to 8 years resulted in a higher incremental cost-effectiveness ratio for liraglutide $1.2 \mathrm{mg}$, as, in this simulation, liraglutide pharmacy costs were accounted 
Table 3 Results of the base-case analysis: quality-adjusted life years (QALYs), costs and incremental cost-effectiveness ratios (ICERs)

\begin{tabular}{|c|c|c|c|c|c|}
\hline & \multicolumn{5}{|c|}{ Liraglutide vs. glimepiride } \\
\hline & $\begin{array}{l}\text { Liraglutide } \\
1.2 \mathrm{mg} \\
+ \text { metformin }\end{array}$ & $\begin{array}{l}\text { Liraglutide } \\
1.8 \mathrm{mg} \\
+ \text { metformin }\end{array}$ & $\begin{array}{l}\text { Sulphonylurea } 4 \text { mg+ } \\
\text { metformin }\end{array}$ & $\begin{array}{l}\text { Difference } \\
\text { liraglutide } \\
1.2 \mathrm{mg}- \\
\text { sulphonylurea }\end{array}$ & $\begin{array}{l}\text { Difference } \\
\text { liraglutide } \\
1.8 \mathrm{mg}- \\
\text { sulphonylurea }\end{array}$ \\
\hline QALYs & $7.76(0.11)$ & $7.73(0.10)$ & $7.44(0.11)$ & $0.32(0.15)$ & $0.28(0.14)$ \\
\hline Costs $(£)$ & $22122(502)$ & $23807(473)$ & $19119(475)$ & $3003(678)$ & $4688(639)$ \\
\hline $\begin{array}{l}\text { ICER } \\
(£ \text { per QALY) }\end{array}$ & - & - & - & 9449 & 16501 \\
\hline
\end{tabular}

\begin{tabular}{|c|c|c|c|c|c|}
\hline & \multicolumn{5}{|c|}{ Liraglutide vs. sitagliptin } \\
\hline & $\begin{array}{l}\text { Liraglutide } \\
1.2 \mathrm{mg} \\
+ \text { metformin }\end{array}$ & $\begin{array}{l}\text { Liraglutide } \\
1.8 \mathrm{mg} \\
+ \text { metformin }\end{array}$ & $\begin{array}{l}\text { Sitagliptin } \\
100 \mathrm{mg} \\
+ \text { metformin }\end{array}$ & $\begin{array}{l}\text { Difference } \\
\text { liraglutide } \\
1.2 \mathrm{mg}- \\
\text { sitagliptin }\end{array}$ & $\begin{array}{l}\text { Difference } \\
\text { liraglutide } \\
1.8 \mathrm{mg}- \\
\text { sitagliptin }\end{array}$ \\
\hline QALYs & $7.52(0.11)$ & $7.64(0.11)$ & $7.34(0.11)$ & $0.19(0.15)$ & $0.31(0.15)$ \\
\hline Costs $(£)$ & $21793(544)$ & $23175(510)$ & $19951(521)$ & $1842(751)$ & $3224(683)$ \\
\hline ICER ( $£$ per QALY) & - & - & - & 9851 & 10465 \\
\hline
\end{tabular}

Data are mean $(\mathrm{SD})$.

for 8 years, with the same clinical benefit of 5 years' treatment. The length of liraglutide treatment for individual patients in a real-life setting will vary, but it is reassuring to note that treatment durations of 3,5 and 8 years are all cost-effective at a willingness to pay of $£ 20000$ per QALY gained (Table 4). Similar trends were observed for liraglutide $1.8 \mathrm{mg}$ (data not shown).

\section{Contribution of clinical effects to QALYs gained}

The results of the additional analyses carried out to investigate the contribution of individual clinical effects (weight, cholesterol and triglycerides, systolic blood pressure and $\mathrm{HbA}_{1 \mathrm{c}}$ ) to QALYs showed that the gain in QALYs with liraglutide $1.2 \mathrm{mg}$ over glimepiride is equally distributed between systolic blood pressure $(32 \%)$, weight $(30 \%)$ and cholesterol and triglycerides $(27 \%)$, with only a smaller contribution from $\mathrm{HbA}_{1 \mathrm{c}}(11 \%)$. Conversely, the gain in QALYs with liraglutide $1.2 \mathrm{mg}$ over sitagliptin arises

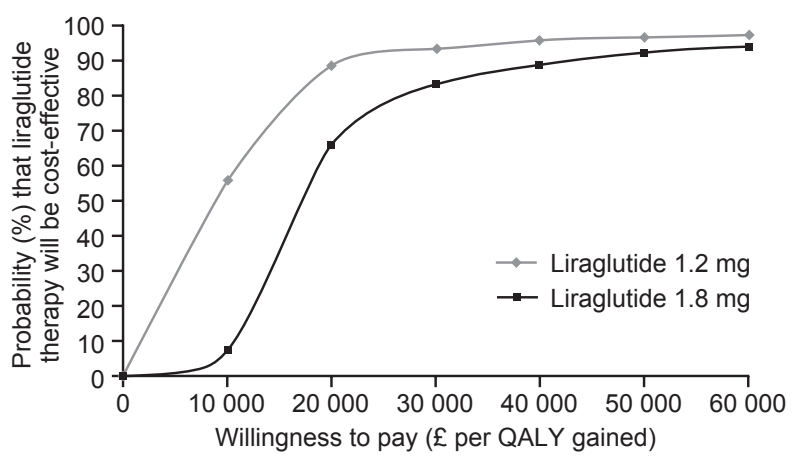

FIGURE 1 Cost-effectiveness acceptability curve of liraglutide vs. glimepiride, base case. QALY, quality-adjusted life year. mainly from improvements in $\mathrm{HbA}_{1 \mathrm{c}}(54 \%)$ and weight $(44 \%)$. Cholesterol and triglycerides and systolic blood pressure changes had a negligible effect on QALYs gained $(-3$ and $-1 \%$, respectively). Additional Supporting Information may be found in the online version of this article.

\section{Discussion}

The cost per QALY vs. glimepiride and vs. sitagliptin, for both doses of liraglutide investigated in this cost-utility modelling study (1.2 and $1.8 \mathrm{mg}$ ), ranged between $£ 9000$ and $£ 16000$. Treatment with liraglutide costs more than with the comparators, but these increased costs were partially offset by reductions in the costs associated with complications, because the risk of developing complications decreases with liraglutide

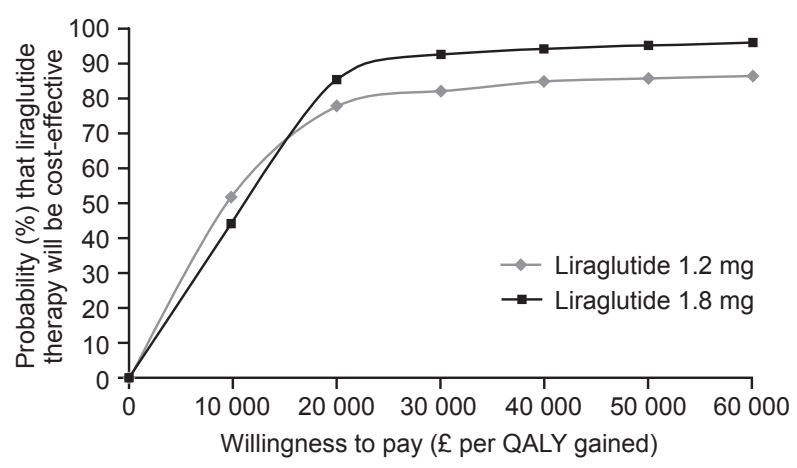

FIGURE 2 Cost-effectiveness acceptability curve of liraglutide vs. sitagliptin, base case. QALY, quality-adjusted life year. 
Table 4 Results of the sensitivity analyses: quality-adjusted life years (QALYs), costs and incremental cost-effectiveness ratios (ICERs)

\begin{tabular}{|c|c|c|c|c|c|c|c|}
\hline \multicolumn{8}{|c|}{ Liraglutide vs. glimepiride } \\
\hline \multirow[b]{2}{*}{ Sensitivity analyses } & \multicolumn{3}{|c|}{ QALYs (years) } & \multicolumn{3}{|c|}{ Costs $(£)$} & \multirow{2}{*}{$\begin{array}{l}\text { ICER } \\
\text { ( } £ \text { per } \\
\text { QALY } \\
\text { gained) }\end{array}$} \\
\hline & $\begin{array}{l}\text { Liraglutide } \\
1.2 \mathrm{mg}\end{array}$ & $\begin{array}{l}\text { Glimepiride } \\
4 \mathrm{mg}\end{array}$ & Difference & $\begin{array}{l}\text { Liraglutide } \\
1.2 \mathrm{mg}\end{array}$ & $\begin{array}{l}\text { Glimepiride } \\
4 \mathrm{mg}\end{array}$ & Difference & \\
\hline Base case & $7.76(0.11)$ & $7.44(0.11)$ & $0.32(0.15)$ & $22122(502)$ & 19119 (475) & $3003(678)$ & 9449 \\
\hline 3 years' treatment & $7.74(0.11)$ & $7.44(0.11)$ & $0.31(0.15)$ & $21463(501)$ & 19975 (477) & $1488(678)$ & 4859 \\
\hline 8 years' treatment & $7.78(0.11)$ & $7.45(0.11)$ & $0.33(0.15)$ & $22983(506)$ & 18005 (472) & $4978(679)$ & 14950 \\
\hline $0 \%$ discount rate & $10924(0.19)$ & $10418(0.19)$ & $0.51(0.26)$ & $34374(936)$ & $30985(90.3)$ & $3389(1300)$ & 6696 \\
\hline $6 \%$ discount rate & $6333(0.10)$ & $6090(0.10)$ & $0.243(0.11)$ & 17108 (358) & $14289(336)$ & $2818(476)$ & 11589 \\
\hline $\begin{array}{l}\text { Alternative weight } \\
\text { progression }\end{array}$ & $7.71(0.11)$ & $7.48(0.11)$ & $0.23(0.15)$ & $22122(502)$ & 19119 (475) & $3003(678)$ & 13175 \\
\hline BMI disutility $=-0.0061$ & $8.04(0.11)$ & $7.77(0.11)$ & $0.27(0.16)$ & $22122(502)$ & 19119 (475) & $3003(678)$ & 11219 \\
\hline $\begin{array}{l}\text { Hypoglycaemia } \\
\text { disutility }=-0.0052\end{array}$ & $7.74(0.11)$ & $7.41(0.11)$ & $0.33(0.15)$ & $22122(502)$ & $19119(475)$ & $3003(678)$ & 9010 \\
\hline $\begin{array}{l}\text { Hypoglycaemia } \\
\text { disutility }=0\end{array}$ & $7.80(0.11)$ & $7.51(0.11)$ & $0.29(0.15)$ & $22122(502)$ & 19119 (475) & $3003(678)$ & 10472 \\
\hline \multicolumn{8}{|c|}{ Liraglutide vs. sitagliptin } \\
\hline & \multicolumn{3}{|c|}{ QALYs (years) } & \multicolumn{3}{|c|}{ Costs $(£)$} & \multirow{2}{*}{$\begin{array}{l}\text { ICER } \\
\text { (£ per } \\
\text { QALY } \\
\text { gained }\end{array}$} \\
\hline Sensitivity analyses & $\begin{array}{l}\text { Liraglutide } \\
1.2 \mathrm{mg}\end{array}$ & $\begin{array}{l}\text { Sitagliptin } \\
100 \mathrm{mg}\end{array}$ & Difference & $\begin{array}{l}\text { Liraglutide } \\
1.2 \mathrm{mg}\end{array}$ & $\begin{array}{l}\text { Sitagliptin } \\
100 \mathrm{mg}\end{array}$ & Difference & \\
\hline Base case & $7.52(0.11)$ & $7.34(0.11)$ & $0.19(0.15)$ & $21793(544)$ & $19951(521)$ & $1842(751)$ & 9851 \\
\hline 3 years' treatment & $7.50(0.10)$ & $7.32(0.11)$ & $0.18(0.14)$ & $21064(532)$ & $20270(521)$ & $793(737)$ & 4321 \\
\hline 8 years' treatment & $7.54(0.11)$ & $7.35(0.11)$ & $0.18(0.15)$ & $22674(534)$ & $19536(520)$ & $3138(715)$ & 16497 \\
\hline $0 \%$ discount rate & $10.49(0.18)$ & $10.19(0.19)$ & $0.30(0.25)$ & 33565 (971) & $31562(938)$ & $2003(1,274)$ & 6720 \\
\hline $6 \%$ discount rate & $6.16(0.08)$ & $6.02(0.08)$ & $0.14(0.11)$ & $16922(401)$ & $15170(383)$ & $1750(528)$ & 12452 \\
\hline $\begin{array}{l}\text { Alternative weight } \\
\text { progression }\end{array}$ & $7.44(0.10)$ & $7.30(0.11)$ & $0.13(0.14)$ & $21793(544)$ & $19951(521)$ & $1842(715)$ & 13752 \\
\hline BMI disutility $=-0.0061$ & $7.86(0.11)$ & $7.70(0.12)$ & $0.16(0.15)$ & $21793(544)$ & $19951(521)$ & $1842(715)$ & 11637 \\
\hline $\begin{array}{l}\text { Hypoglycaemia } \\
\text { disutility }=-0.0052\end{array}$ & $7.50(0.10)$ & $7.31(0.11)$ & $0.19(0.15)$ & $21793(544)$ & $19951(521)$ & $1842(715)$ & 9852 \\
\hline $\begin{array}{l}\text { Hypoglycaemia } \\
\text { disutility }=0\end{array}$ & $7.55(0.11)$ & $7.36(0.11)$ & $0.19(0.15)$ & $21793(544)$ & $19951(521)$ & $1842(715)$ & 9686 \\
\hline
\end{tabular}

Data are mean $(\mathrm{SD})$.

treatment as a result of its combined beneficial effects on body weight, blood glucose, systolic blood pressure and other cardiovascular risk factors. The values obtained lie below the threshold of $£ 20000-30000$ per QALY, indicating that liraglutide in combination with metformin monotherapy is a cost-effective option for the treatment of Type 2 diabetes compared with glimepiride or sitagliptin. The sensitivity analyses performed indicated that, in the liraglutide vs. glimepiride comparison, systolic blood pressure, weight and cholesterol were the key drivers of cost-effectiveness, with a relatively small contribution from $\mathrm{HbA}_{1 \mathrm{c}}$. This was to be expected, as both liraglutide and glimepiride treatment achieved similar $\mathrm{HbA}_{1 \mathrm{c}}$ reductions in the clinical trial on which this health economic evaluation is based, while liraglutide had a greater impact on reducing systolic blood pressure, weight and cholesterol compared with glimepiride [10]. In contrast, $\mathrm{HbA}_{1 \mathrm{c}}$ and weight were the key drivers of cost-effectiveness in the liraglutide vs. sitagliptin comparison, with only small effects from systolic blood pressure and cholesterol, reflecting the greater effect of liraglutide vs. sitagliptin on reducing $\mathrm{HbA}_{1 \mathrm{c}}$ and weight, and the comparable effects of both of these therapies on systolic blood pressure and cholesterol [11]. In the liraglutide vs. sitagliptin comparison, a preliminary subgroup analysis in which patients were stratified by baseline BMI (all > 30 or $>35 \mathrm{~kg} / \mathrm{m}^{2}$ ) showed that the cost-effectiveness of liraglutide $1.2 \mathrm{mg}$ vs. sitagliptin improved with increasing BMI, with incremental costeffectiveness ratios of $£ 9851, £ 7593$ and $£ 6125$, respectively (see also Supporting Information, Table S3), probably because weight loss with liraglutide increases with increasing BMI [19]. This initial finding is interesting and may warrant further investigation at a later date. Treatment satisfaction was also assessed in the liraglutide vs. sitagliptin clinical trial using the 
Diabetes Treatment Satisfaction Questionnaire (DTSQ) and patients reported greater treatment satisfaction with liraglutide [11]. This result was not taken into consideration in the costutility analysis presented here. However, had it been, the costeffectiveness of liraglutide vs. sitagliptin may have been even further enhanced, as treatment satisfaction could translate into greater adherence and improved clinical outcomes [20]. Furthermore, contrary to the perception that oral treatments are usually preferred to injections, there were no differences in the perceived convenience of treatment between sitagliptin and liraglutide [11].

To put the results of this economic evaluation into context, the cost per QALY of implementing liraglutide in combination with metformin therapy estimated in this study is in the same range as that estimated for implementing education programmes aimed at maximizing the benefits of diet and lifestyle interventions as reported in a recent study, which estimated a cost per QALY ranging from $€ 10000$ to $€ 39000$ [21]. However, a study that investigated the cost-effectiveness of the Diabetes Education and Self management for Ongoing and Newly Diagnosed (DESMOND) programme in UK patients newly diagnosed with Type 2 diabetes reported a lower cost per QALY of $£ 2092$ [22]. The estimated cost per QALY of adding pioglitazone to ongoing therapy in patients with Type 2 patients with a history of macrovascular disease and at high risk for further cardiovascular events was reported as $£ 5396$ vs. placebo after a mean treatment period of 3 years [23].The cost of adding sitagliptin to metformin monotherapy vs. the cost of adding a sulphonylurea appears to also be in the same range as the cost of adding liraglutide to metformin monotherapy reported here. An analysis to evaluate the cost of adding sitagliptin vs. sulphonylurea to metformin monotherapy in patients with Type 2 diabetes from six European countries (Austria, Finland, Portugal, Scotland, Spain and Sweden) and not reaching the International Diabetes Federation's $\mathrm{HbA}_{1 \mathrm{c}}$ target of $<48 \mathrm{mmol} / \mathrm{mol}(<6.5 \%)$ estimated costs per QALY ranging from $€ 5949$ to $€ 20350$ across countries [24]. Similarly, the cost per life-year with statins, a common therapy used in patients with Type 2 diabetes concomitantly with anti-hyperglycaemic agents to treat dyslipidaemia and reduce cardiovascular risk, has been estimated to range from $£ 5400$ to $£ 13300$ for primary prevention and from $£ 3800$ to $£ 9300$ for secondary prevention. [25]

A limitation of this study is that the model used, like all models used to assess the long-term outcomes of patients with Type 2 diabetes, predicts long-term outcomes based on the results of short-term studies. However, the CORE Diabetes Model used here has been validated against published studies that had not been used to provide input data for setting up the model [13]. For each validation analysis, the progress of a patient cohort from a published epidemiological, clinical or modelling study was simulated, and the outcomes of the simulation were compared with those of the published study. The results indicated that the CORE Diabetes Model is capable of reliably predicting longterm patient outcomes.
In conclusion, this study investigated the cost-utility, in a UK setting, of liraglutide vs. glimepiride or sitagliptin (all added to metformin monotherapy), scenarios intended to simulate likely clinical practice in real life. The results suggest that liraglutide added to metformin monotherapy leads to improvements in quality adjusted-life expectancy and is a cost-effective option for the treatment of Type 2 diabetes in this setting.

\section{Competing interests}

The study was funded by Novo Nordisk, the manufacturer of liraglutide. Novo Nordisk was responsible for running the model and analysing and reporting the results. The authors were responsible for the decision to submit the manuscript for publication. MJD has received advisory board and speaker and consultancy fees from Novo Nordisk and has received funding for research trials. BDC is employed by Novo Nordisk. ICS is employed by and owns shares in Novo Nordisk. WJV has received consultancy fees from Novo Nordisk.

\section{Acknowledgements}

We would like to acknowledge Andrew Palmer and Stefané Roze for the development of the CORE Diabetes Model, IMS Health for the ongoing maintenance, development and access to the CORE Diabetes Model and Watermeadow Medical, supported by Novo Nordisk, for medical writing and editorial assistance.

\section{References}

1 World Health Organization. Diabetes. Fact sheet no. 312. 2009. Available at http:/www.who.int/mediacentre/factsheets/fs312/en/ Last accessed 14 January 2011.

2 Williams R, Van Gaal L, Lucioni C. Assessing the impact of complications on the costs of type II diabetes. Diabetologia 2002; 45 : S13-S17.

3 Koopmanschap M. Coping with type II diabetes: the patient's perspective. Diabetologia 2002; 45: S18-S22.

4 National Collaborating Centre for Chronic Conditions. Type 2 Diabetes: National Clinical Guideline for Management in Primary and Secondary Care (update). London: Royal College of Physicians, 2008.

5 Stratton IM, Adler AI, Neil HAW, Matthews DR, Manley SE, Cull CA et al. Association of glycaemia with macrovascular and microvascular complications of type 2 diabetes (UKPDS 35): prospective observational study. $\mathrm{Br}$ Med J 2000; 321: 405-412.

6 National Institute for Health and Clinical Excellence. Type 2 Diabetes: Newer Agents for Blood Glucose Control in Type 2 Diabetes. 2009. Available at http://guidance.nice.org.uk/CG87/ Guidance/pdf/English Last accessed 14 January 2011.

7 National Institute for Health and Clinical Excellence. Final Appraisal Determination. Liraglutide for the Treatment of Type 2 Diabetes. 2010. Available at http://www.nice.org.uk/nicemedia/ live/11895/50663/50663.pdf Last accessed 14 January 2011.

8 Nathan DM, Buse JB, Davidson MB, Ferrannini E, Holman RR, Sherwin R. Medical management of hyperglycemia in type 2 diabetes: a consensus algorithm for the initiation and adjustment of therapy. Diabetes Care 2009; 32: 193-203.

9 White J. Efficacy and safety of incretin-based therapies: clinical trial data. J Am Pharm Assoc 2009; 49: S30-S40. 
10 Nauck MA, Frid A, Hermansen K, Shah NS, Tankova T, Mitha IH et al., LEAD-2 Study Group Efficacy and safety comparison of liraglutide, glimepiride, and placebo, all in combination with metformin in type 2 diabetes. Diabetes Care 2009; 32: 84-90.

11 Pratley RE, Nauck M, Bailey T, Montanya E, Cuddihy R, Filetti S et al., for the 1860-LIRA-DPP-4 Study Group Liraglutide versus sitagliptin for patients with type 2 diabetes who did not have adequate glycaemic control with metformin: a 26-week, randomised, parallel-group, open-label trial. Lancet 2010; 375: 1447-1456.

12 Palmer AJ, Roze S, Valentine WJ, Minshall ME, Foos V, Lurati FM et al. The CORE Diabetes Model: projecting long-term clinical outcomes, costs and cost-effectiveness of intervention in diabetes mellitus (types 1 and 2) to support clinical and reimbursement decision making. Curr Med Res Opin 2004; 20: S5-S26.

13 Palmer AJ, Roze S, Valentine WJ, Minshall ME, Foos V, Lurati FM et al. Validation of the CORE Diabetes Model against epidemiological and clinical studies. Curr Med Res Opin 2004; 20: S27-S40.

14 National institute for Health and Clinical Excellence. Measuring Effectiveness and Cost Effectiveness: the QALY. 2010. Available at http://www.nice.org.uk/newsroom/features/measuringeffectivenessandcosteffectivenesstheqaly.jsp Last accessed 14 January 2011.

15 Haymarket Publications. Monthly Index of Medical Specialities (MIMS), August 2009 edition. London: Haymarket Publications, 2009.

16 National institute for Health and Clinical Excellence. Guide to the Methods of Technology Appraisal. 2008. Available at http://www. nice.org.uk/media/B52/A7/TAMethodsGuideUpdatedJune2008.pdf Last accessed 27 March 2011.

17 Tarn T, Smith M. Pharmacoeconomic guidelines around the world. ISPOR Connections 2004; 10: 5-15.

18 National Institute for Clinical Excellence. Guidance on the Use of Long-Acting Insulin Analogues for the treatment of Diabetes Insulin Glargine (TA53). 2002. Available at http://www.nice. org.uk/nicemedia/pdf/53_Insulin_analogues_full_guidance.pdf Last accessed 14 January 2011.

19 Russell-Jones D, Nauck M, Brandle M, Vaag A, Colagiuri S, Schmitz O et al. The once-daily human GLP-1 analogue liraglutide reduces body weight in subjects with type 2 diabetes, irrespective of body mass index at baseline. Diabetes 2006; 57: A593.

20 Brod M, Cobden D, Lammert M, Bushnell D, Raskin P. Examining correlates of treatment satisfaction for injectable insulin in type 2 diabetes: lessons learned from a clinical trial comparing biphasic and basal analogues. Health Qual Life Outcomes 2007; 5: 8.

21 Jacobs van der Bruggen MAM, Van Baal PH, Hoogenveen RT, Feenstra TL, Briggs AH, Lawson $\mathrm{K}$ et al. Cost-effectiveness of lifestyle modification in diabetic patients. Diabetes Care 2009; 32: 1453-1458.
22 Gillett M, Dallosso HM, Brennan A, Carey ME, Campbell MJ, Heller $\mathrm{S}$ et al. Delivering the diabetes education and self management for ongoing and newly diagnosed (DESMOND) programme for people with newly diagnosed type 2 diabetes: cost-effectiveness analysis. Br Med J 2010; 341: c4093.

23 Valentine WJ, Bottmley JM, Palmer AJ, Brändle M, Foos V, Williams $\mathrm{R}$ et al. PROactive 06: cost-effectiveness of pioglitazone in Type 2 diabetes in the UK. Diabet Med 2007; 24: 982-1002.

24 Schwarz B, Gouveia M, Chen J, Nocea G, Jameson K, Cook J et al. Cost-effectiveness of sitagliptin-based treatment regimens in European patients with type 2 diabetes and haemoglobin A1c above target on metformin monotherapy. Diabetes Obes Metab 2008; 10: S43-S55.

25 Ebrahim S, Davey Smith G, McCabe C, Payne N, Pickin M, Sheldon TA et al. What role for statins? A review and economic model. Health Technol Assess 1999; 3: i-iv 1-91.

26 Scottish Diabetes Survey Monitoring Group. Scottish Diabetes Survey 2007. 2007. Available at http://www.diabetesinscotland. org.uk/Publications/Scottish\%20Diabetes\%20Survey\%202007.pdf Last accessed 14 January 2011.

\section{Supporting Information}

Additional Supporting Information may be found in the online version of this article:

Table S1. Summary of the costs of medicines and complications used in the model adjusted to 2008 costs.

Table S2. Summary of utilities and disutilities for the base case used in the model.

Table S3. Results of the base-case analysis by BMI subgroup in the liraglutide vs. sitagliptin comparison: quality-adjusted life years, costs and incremental cost-effectiveness ratios.

Appendix S1. Reference list.

Please note: Wiley-Blackwell are not responsible for the content or functionality of any supporting materials supplied by authors. Any queries (other than for missing material) should be directed to the corresponding author for the article. 